\title{
Madelung deformity: A Case Report
}

\author{
Rita Coelho Lopes ${ }^{1}$, Hugo Fernandes ${ }^{1}$, Ana Bia ${ }^{2}$ and Margarida Carvalho ${ }^{3 *}$ \\ ${ }^{1}$ Orthopedic Resident, Public Hospital Center, Portugal \\ ${ }^{2}$ Orthopedic Medical Doctor, Public Hospital Center, Portugal \\ ${ }^{3}$ Orthopedic Senior Consultant, Public Hospital Center, Portugal
}

Submission: August 01, 2017; Published: August 09, 2017

*Corresponding author: Margarida Carvalho, Orthopedic Senior Consultant, Public Hospital Center, Torres Vedras, Portugal,

Tel: 00351967885 800; Email: margcarv@gmail.com

\begin{abstract}
Madelung deformity is a rare abnormality of the wrist, representing $1.7 \%$ of the congenital diseases of the child. It is characterized by volar and medial displacement of the radial joint surface with radius bowing, triangular aspect of the carpus and ulnar head lateral and posteriorly subluxated. The disorder is most common in female patients, becoming evident clinically between the ages of 6 and 13 years. There are numerous proposed surgical techniques. We report the case of a 14 years old female referred by bilateral deformity and limited wrist mobility as well as pain in the right wrist lasting for more than one year. The radiograph shows a malformation of the radial distal epiphysis suggestive of bilateral Madelung deformity.
\end{abstract}

A triplane osteotomy of the distal radius metaphysic with Vicker's ligament release, and ulnar shortening osteotomy was performed on the right side. At 6 months postoperatively, there was aesthetic improvement, recovery of supination of the right wrist and no pain. One year after surgery there is no relapses and patient is very satisfied with the good esthetical and functional result and painless. It is a rare disease, that when diagnosed and treated properly may improve the mobility and function of the wrist, and so the adolescent's quality of life.

Keywords: Madelung deformity; Children; Radius; Ulna; Surgery

\section{Case Description}

14-years old Caucasian female, pre-menarche, who presented wrist mechanical pain and limitation of supination and extension of the right forearm lasting for more than one year (dominant hand).Physical examination (Figure 1) revealed ulnar head prominent, volar tilting of the carpus and hand, painful limitation of extension $\left(10^{\circ}\right)$ and supination $\left(20^{\circ}\right)$ of the wrist. The blood cell count and the blood chemistry were normal. The familiar history was positive for grandmother's deformity similar to her own, although less symptomatic.
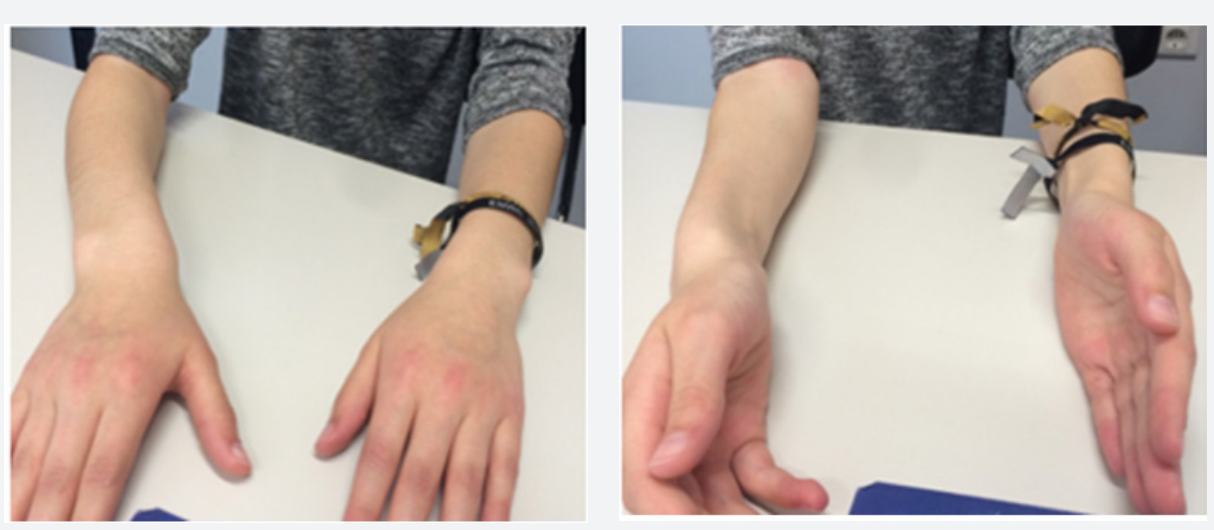

Figure 1: Physical exam at presentation. 


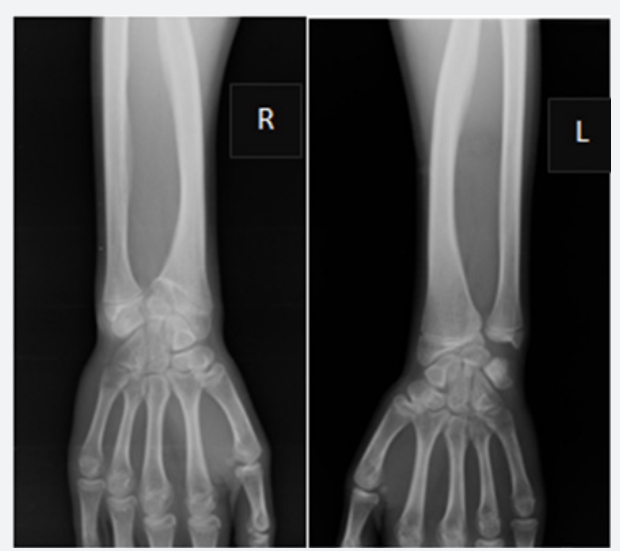

Figure 2: Posteroanterior X-rays at presentation.

The postero anterior wrist X-rays (Figure 2) showed typical Madelung deformity changes on both wrists: shortening of the radius compared to the ulna, radially curved radius, a mismatch of the distal radioulnar joint and a triangular-shaped carpus. The lateral projection (Figure 3) demonstrated predominant changes on the right wrist: dorsal dislocation of the ulnar and an exaggerated volar tilt of the radioulnar joint in a way that made palmar carpal displacement and an anterior translation of the hand and the wrist. It was performed on the right side ametaphysic triplane osteotomy of the distal radius with Vicker's ligament release, and an ulnar shortening osteotomy with plate fixation (Figure 4). There was no intra and postoperative complications.

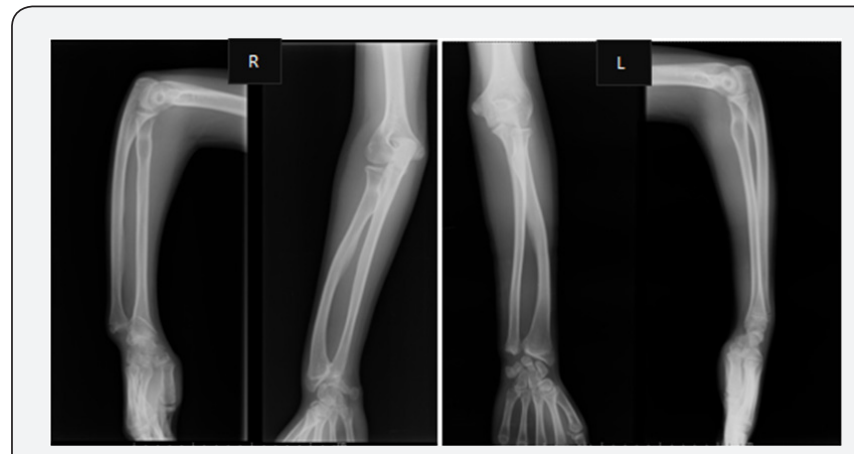

Figure 3: Lateral X-rays at presentation.

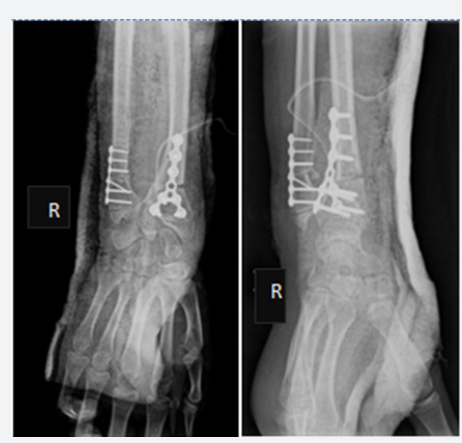

Figure 4: Immediate postoperativeradiographic images.
Osteotomies were protected with dorsal forearm plaster splint for 3 weeks. Postoperative management depends on what is done. Cast immobilization may be necessary for some weeks after an osteotomy of the radius or ulna. Physiotherapy may be necessary in children who are not able to regain range of motion on their own after 2-3 months without restrictions. In our case no physiotherapy was needed. After 12 months, there was no pain, a good aesthetic and mobility improvement of the right wrist, mainly of prone-supination (Figure5). The radiographic images (Figure 6) showed good alignment and healing of the bone.
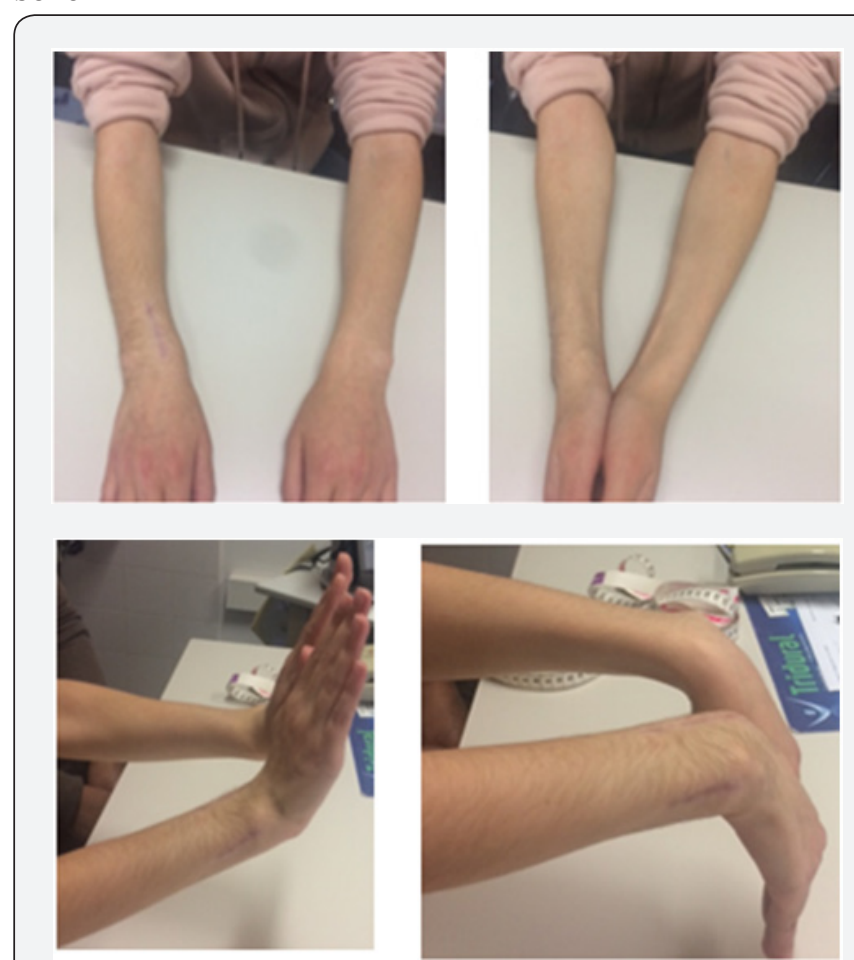

Figure 5: Physical exam after 12 months of surgery.

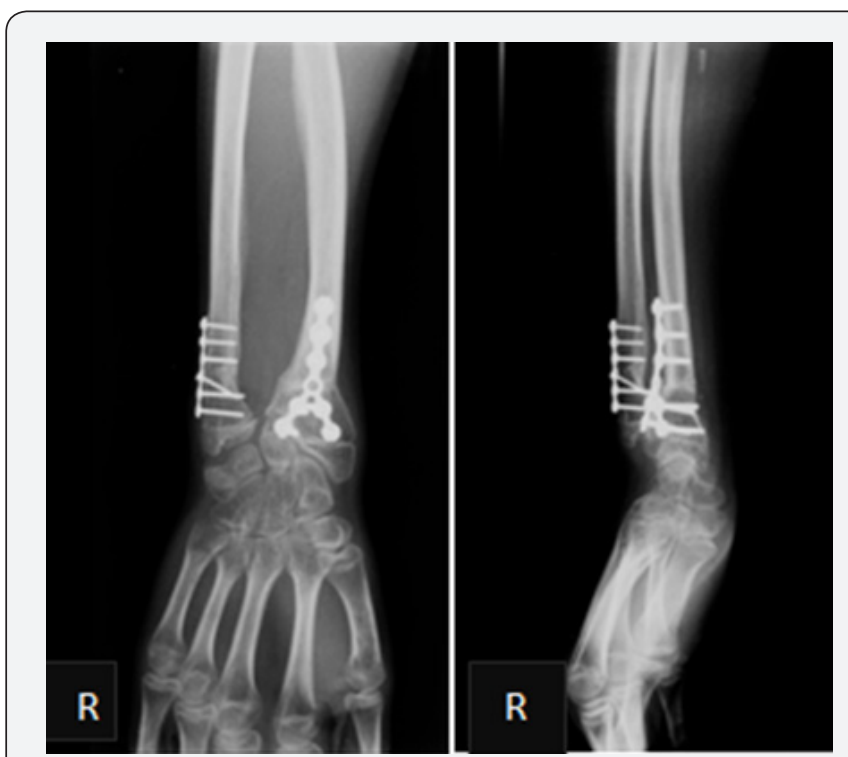

Figure 6: Radiographic images after 12 months of surgery. 


\section{Discussion}

The Madelung deformity is a rare disease, representing $1.7 \%$ of the congenital diseases [1]. It is associated with Vicker's ligament that creates a tether across the volar-ulnar radial physis, which results in premature growth plate arrest at the medial volar aspect of the distal radius [2]. As the remaining physis grows, the radius deforms with increasing radial inclination and increasing volar tilt; the unaffected ulna continues to elongate, yielding a progressive ulnar positive variance [2]. Ultimately, the distal radioulnar joint fails to form normally and the distal ulna subluxates or dislocates in a dorsal direction [2].

Congenital Madelung deformity can occur as a part of LeriWeill dyschondrosteosis or Turner syndrome and it is thought to be a result of a mutation or absence of the short stature homebox gene (SHOX). Madelung-like deformity can be acquired as the result of repetitive traumatic pressure [3]. The disorder is most prevalent in female patients, at a ratio of 3 to 5:1 [3], becoming evident clinically between the ages of 6 and 13 years (5). Patients report wrist pain, impaired grip strength, limited range of motion (commonly supination) and disfigurement based on their prominent ulna $[1,3]$. The spectrum of presentation is broad and therefore the presenting symptoms are heterogeneous.

Madelung deformity can be diagnosed with anteroposterior and lateral wrist radiographs. Specific thresholds have been determined to most accurately detect Madelung deformity. These limits are at least $33^{\circ}$ of ulnar tilt, at least $4 \mathrm{~mm}$ of lunate subsidence, lunate fossa angle of $40^{\circ}$ or more and $20 \mathrm{~mm}$ or more of palmar carpal displacement [4-6]. Radiological deformity does not systematically correspond to functional disorder or pain and the functional impairment found in certain cases would require complementary analysis of structural lesions, preferably by MRI [3].

Treatment depends on the age at presentation and distal ulnar growth potential, magnitude of symptomsand degree of deformity $[2,7]$. Progressive deformities in children with considerable remaining growth potential, advance deformity or symptomatic are indications for surgery to prevent ongoing deterioration [2]. There is no universally preferred surgical strategy. Today's standard of care is a radial dome osteotomy with Vicker's ligament release [5]. Ulnar approachmay be undertaken in severe cases, including increased lunate subsidence, ulnar variance and volar carpal displacement [5], to achieve more appropriate length symmetry between the radius and ulna. Although the techniques vary considerably, each can be categorized into 1 of 3 groups: the first group applied to the radius alone includes epiphysiodesis and corrective osteotomy; the second group involves repair and reconstruction limited to the ulna including epiphysiodesis, ulnar head excision, shortening osteotomy, distal ulnar resection and creation of a pseudarthrosis with or without fusion to the radius; the third group involves some combination of the above techniques [8]. Mild asymptomatic deformity warrants a period of nonsurgical management with serial $x$-ray examinations because the natural history is unpredictable; many patients never require surgical intervention [2].

The technique we described aims to restore the anatomy of the wrist to as normal as possible, in order to relieve pain, acquire esthetic correction and improve joint motion. We joined both bones osteotomies, to restore immediately the anatomy, to Vicker's ligament release to prevent loss of correction in the future. Our result after one year follow up show that grip strength and range of movement improved significantly; there is no pain and the patient is satisfied with the esthetic appearance.

\section{Conclusion}

It is a rare deformity that, when diagnosed and treated properly may improve the mobility and function of the wrist, and so the adolescent's quality of life. Our technique produced good results for the treatment of the Madelung deformity.

\section{References}

1. Arora AS, Chung KC, Otto W (2006) Madelung and the Recognition of Madelung's Deformity. J Hand Surg 31(2): 177-182.

2. Kozin SH, Zlotolow DA (2015) Madelung Deformity. J Hand Surg Am 40(10): 2090-2098.

3. Huguet S (2014) Radiological and clinical analysis of Madelung's deformity in children. Orthopedics \& Traumatology: Surgery \& Research 100: 349-352.

4. Ghatan AC, Hanel DP (2013) Madelung deformity. J Am AcadOrthop Surg 21: 372-382.

5. Tranmer A, Laub D (2016) Madelung deformity. Interesting Case.

6. McCarroll HR, James MA, Newemeyer WL, Manske PR (2010) Madelung's deformity: Diagnostic thresholds of radiographic measurements. J Hand Surg Am 35: 807-812.

7. Ly-Pen D, Andreu JL (2014) Madelung's deformity. ReumatolClin 10(2): 125-126.

8. Brooks TJ (2001) Madelung deformity in a collegiate gymnast: a case report. Journal of Athletic Training 36(2): 170-173. 
This work is licensed under Creative Commons Attribution 4.0 Licens DOI: 10.19080/OAJS.2017.05.555657
Your next submission with Juniper Publishers will reach you the below assets

- Quality Editorial service

- Swift Peer Review

- Reprints availability

- E-prints Service

- Manuscript Podcast for convenient understanding

- Global attainment for your research

- Manuscript accessibility in different formats

( Pdf, E-pub, Full Text, Audio)

- Unceasing customer service

Track the below URL for one-step submission https://juniperpublishers.com/online-submission.php 